TEIXEIRA, Elisângela Sampaio; CORRALO, Giovani da Silva. Governança local e conselhos municipais - diálogo necessário para sustentabilidade e preservação do meio ambiente. Revista Eletrônica Direito e Política, Programa de Pós-Graduação Stricto Sensu em Ciência Jurídica da UNIVALI, Itajaí, v.10, n.1, edição especial de 2015. Disponível em: www.univali.br/direitoepolitica ISSN 1980-7791.

\title{
GOVERNANÇA LOCAL E CONSELHOS MUNICIPAIS - DIÁLOGO NECESSÁRIO PARA SUSTENTABILIDADE E PRESERVAÇÃO DO MEIO AMBIENTE
}

\author{
LOCAL GOVERNANCE AND MUNICIPAL COUNCILS - DIALOGUE NECESSARY FOR \\ SUSTAINABILITY AND ENVIRONMENTAL PRESERVATION
}

\author{
Elisângela Sampaio Teixeira ${ }^{1}$ \\ Giovani da Silva Corralo²
}

\begin{abstract}
SUMÁRIO: Introdução; 1 . Governança pública municipal; 2. Sistema nacional de meio ambiente e os Conselhos Municipais de Meio Ambiente; 3. A busca pelo amadurecimento entre governança pública e conselho municipal do meio ambiente; Considerações finais ; Referências das fontes citadas .
\end{abstract}

RESUMO: Conciliar interesses que visam ao crescimento econômico, ao cumprimento das normas brasileiras em matéria ambiental e aos interesses da sociedade é considerado de extrema relevância para uma boa administração pública. O presente artigo tem como objetivo tecer algumas considerações sobre governança municipal e a sua importância no cumprimento da legislação ambiental e sua relação com a democracia participativa através dos conselhos municipais de meio ambiente. O governo local ao planejar, formular e implementar políticas públicas que, de alguma forma, atinjam o meio ambiente deve almejar promover o desenvolvimento econômico de forma sustentável. Uma eficiente governança exige transparência dos atos públicos e participação democrática para dialogar e compreender os interesses locais. Neste sentido, vislumbra-se nos conselhos municipais a possibilidade de vínculo entre a administração pública e a sociedade civil para que juntos possam discutir soluções e diminuir conflitos de interesses e, assim, cumprir com o disposto no artigo 225 da Constituição Federal.

\footnotetext{
${ }^{1}$ Mestranda em Direito pelo Programa de Pós Graduação da Faculdade de Direito da UPF, bolsista Prosup/ Capes. Advogada. E-mail: elisangelateixeira.adv@gmail.com

2 Doutor e Mestre em Direito do Estado pela Universidade Federal do Paraná. Especialista em Advocacia Municipal pela UFRGS. Professor da Faculdade de Direito e do Curso de Mestrado da Universidade de Passo Fundo. Advogado.
} 
TEIXEIRA, Elisângela Sampaio; CORRALO, Giovani da Silva. Governança local e conselhos municipais - diálogo necessário para sustentabilidade e preservação do meio ambiente. Revista Eletrônica Direito e Política, Programa de Pós-Graduação Stricto Sensu em Ciência Jurídica da UNIVALI, Itajaí, v.10, n.1, edição especial de 2015. Disponível em: www.univali.br/direitoepolitica ISSN 1980-7791.

Palavras-chave: Governança Pública; Município; Conselhos Municipais; Sustentabilidade.

ABSTRACT: Reconciling interests that seek economic growth, compliance with Brazilian environmental standards and the interests of society is considered extremely important for a good public administration. This article aims to present some considerations on municipal governance and its importance in environmental compliance and its relation to participatory democracy through the municipal environmental councils. The local government in planning, formulating and implementing public policies that, somehow, reach the environment should aim to promote economic development in a sustainable manner. Effective governance requires transparency of public acts and democratic dialogue and to understand local participation interests. In this sense it is envisaged in the municipal councils the possibility of a link between government and civil society so that together we can discuss solutions and reduce conflicts of interest, and thus comply with the provisions of Article 225 of the Federal Constitution.

Keywords: Public Governance; Municipality; Municipal Councils; Sustainability.

\section{INTRODUÇÃo}

O presente trabalho tem como objetivo tecer algumas considerações sobre a relevância da governança municipal e a relação desta com a participação dos cidadãos nos conselhos municipais de meio ambiente para uma maior concretização dos interesses locais no cumprimento das políticas ambientais, pois a proteção do meio ambiente é uma conquista de todos e encontra-se inserida sob a égide da tutela dos direitos fundamentais.

O desenvolvimento econômico através da gestão pública deve harmonizar-se com o desenvolvimento social saudável, buscando-se, assim, um desenvolvimento econômico sustentável. Portanto, os atos praticados tanto por gestores públicos como por gestores privados não devem ter resultados nocivos ao meio ambiente tal como tutelado no art. 225 da Constituição Federal (CF).

Canotilho explica que, após a superação do Estado Liberal de Direito e com o advento do Estado do bem-estar social, os direitos fundamentais passam para além de uma concepção individual, ou seja, passa-se a reconhecê-los também 
TEIXEIRA, Elisângela Sampaio; CORRALO, Giovani da Silva. Governança local e conselhos municipais - diálogo necessário para sustentabilidade e preservação do meio ambiente. Revista Eletrônica Direito e Política, Programa de Pós-Graduação Stricto Sensu em Ciência Jurídica da UNIVALI, Itajaí, v.10, n.1, edição especial de 2015. Disponível em: www.univali.br/direitoepolitica ISSN 1980-7791.

como "proteção e à materialização de bens considerados importantes para a comunidade" ${ }^{3}$.

Cita-se como exemplo relevante do vínculo entre direito fundamental e meio ambiente o direito à saúde, direito social fundamental previsto no art. $6^{\circ}$, da CF. Complementa ainda o art. 196 da CF: "A saúde é direito de todos e dever do Estado, garantido mediante políticas sociais e econômicas que visem à redução do risco de doença e de outros agravos e ao acesso universal e igualitário às ações e serviços para sua promoção, proteção e recuperação" ${ }^{\prime 4}$. Atualmente, uma das questões ambientais cruciais à saúde tem sido a poluição, sendo que a competência para efetivar políticas públicas para diminuí-la e combatê-la é dos três entes da federação - União, Estados e Municípios - tal como determinado no inciso VI, art.23, CF.

Neste sentido, sempre houve inúmeras decisões do Supremo Tribunal Federal que abordaram e ainda abordam a relação da proteção a um meio ambiente equilibrado como um direito fundamental de terceira geração. Encontra-se exposto na Ação Direita de Constitucionalidade n. 3540 - que a preservação da integridade do meio ambiente é uma expressão constitucional de um direito fundamental que assiste à generalidade das pessoas, abaixo citado:

Todos têm direito ao meio ambiente ecologicamente equilibrado. Trata-se de um típico direito de terceira geração (ou de novíssima dimensão), que assiste a todo o gênero humano (RTJ 158/205-206). Incumbe, ao Estado e à própria coletividade, a especial obrigação de defender e preservar, em benefício das presentes e futuras gerações, esse direito de titularidade coletiva e de caráter transindividual (RTJ 164/158-161). O adimplemento desse encargo, que é irrenunciável, representa a garantia de que não se instaurarão, no seio da coletividade, os graves conflitos intergeneracionais marcados pelo desrespeito ao dever de

3 CANOTILHO, José Joaquim Gomes. LEITE, José Rubens Morato. Direito constitucional ambiental brasileira. 3. ed. São Paulo, SP: Editora Saraiva, 2010, p.215.

${ }^{4}$ BRASIL. Constituição da República Federativa do Brasil de 05 de outubro de 1988. Disponível em: http://www.planalto.gov.br/ccivil_03/constituicao/constituicao.htm. Acesso em: 22 de setembro de 2014. 
TEIXEIRA, Elisângela Sampaio; CORRALO, Giovani da Silva. Governança local e conselhos municipais - diálogo necessário para sustentabilidade e preservação do meio ambiente. Revista Eletrônica Direito e Política, Programa de Pós-Graduação Stricto Sensu em Ciência Jurídica da UNIVALI, Itajaí, v.10, n.1, edição especial de 2015. Disponível em: www.univali.br/direitoepolitica ISSN 1980-7791.

solidariedade, que a todos se impõe, na proteção desse bem essencial de uso comum das pessoas em geral ${ }^{5}$.

Discutir sobre as possibilidades de efetivação deste direito fundamental a um meio ambiente equilibrado e sustentável é relevante para a comunidade acadêmica visto que se trata de assunto cotidiano e diariamente violado pelos entes públicos. O objetivo do presente trabalho é analisar a importância da relação da governança municipal e os conselhos municipais para o cumprimento não só de sua competências ambientais municipais como também na efetivação de suas políticas públicas. Afinal, o art. $3^{\circ}$ da Lei Federal nº. 140/2011 define diversas competências ambientais em comum do Município com os Estados e com a União.

Estabeleceu-se, ainda, no inciso I do art. 30 da Constituição Federal, que o município tem competência para legislar sobre assunto de interesse local, sendo competente não só para exercer a fiscalização em matéria ambiental, deliberações e autorizações como também possui competência legislativa.

Para desenvolver o trabalho, utilizou-se o método de pesquisa teórica ${ }^{6}{ }^{7}$ através da qual se analisou conteúdo das leis, consulta de livros e jurisprudências pertinentes ao assunto.

\section{GOVERNANÇA PÚBLICA MUNICIPAL}

A governança pública tem sido amplamente discutida não só por organismos internacionais como também pelo governo brasileiro seja em nível federal, estadual ou municipal. A expressão "governança" surge a partir de discussões promovidas pelo Banco Mundial onde formulou-se o conceito de que governança

\footnotetext{
${ }^{5}$ BRASIL. Supremo Tribunal Federal. Acordão. Ação Direta de Inconstitucionalidade n. 3540. Relator: MELLO, Celso de. Tribunal Pleno, Publicado no DJ de 03-02-2006; EMENTA VOL-02219-03 PP-00528, disponível em: http://www.stf.jus.br/portal/principal/principal.asp. Acesso em: 22 de setembro de 2014.

${ }^{6}$ GUSTIN, Miracy Barbosa de Souza. DIAS, Maria Tereza Fonseca. (Re)pensando a pesquisa jurídica: teoria e prática. Belo Horizonte, BH: Editora Del Rey, 2010, p.106.

7 BASTOS, Cleverson Leite. KELLER, Vicente. Aprendendo a aprender: introdução à metodologia científica. Petrópolis, RJ: Editora Vozes, 2008, p.60.
} 
TEIXEIRA, Elisângela Sampaio; CORRALO, Giovani da Silva. Governança local e conselhos municipais - diálogo necessário para sustentabilidade e preservação do meio ambiente. Revista Eletrônica Direito e Política, Programa de Pós-Graduação Stricto Sensu em Ciência Jurídica da UNIVALI, Itajaí, v.10, n.1, edição especial de 2015. Disponível em: www.univali.br/direitoepolitica ISSN 1980-7791.

é o modo como o governo exerce o poder para administrar seus recursos sociais e financeiros e, com isso, promover o desenvolvimento e implementar suas políticas governamentais ${ }^{8}, 9$.

A governança é exercida através das instituições que possuem autoridade num país, estas, por sua vez, deveriam buscar gerenciar seus recursos de modo eficiente, formulando e implementando propostas de políticas públicas através de regras sólidas e transparentes ${ }^{10}$. A autora complementa que as propostas de uma boa governança dão-se através da escolha dos governantes que, por sua vez, podem ser monitorados, responsabilizados e substituídos de seus cargos.

Complementa Assis ${ }^{11}$ que governança "significa um novo modo de governo, ou seja, uma forma mais cooperativa de governar, diferente do velho modelo hierárquico nos quais os estados autoritários exerciam controle externo sobre grupos de cidadãos."

Segundo diversos autores, é preciso diferenciar governo, governança e governabilidade. Governo abarca unicamente a dimensão estatal empoderada democraticamente para a formulação e implementação de políticas públicas, a governança remete à maneira pela qual o governo, a sociedade organizada e seus cidadãos buscam o desenvolvimento e resolvem os seus problemas. Difere a governança, também, da governabilidade, pois esta também está atrelada à

\footnotetext{
${ }^{8}$ GONÇALVES, A. O Conceito de Governança. Congresso Nacional do CONDEPI, XIV, 2005, Fortaleza. Anais. Florianópolis: Fundação Boileux; 2006.

${ }^{9}$ WORLD BANK. Governance and Development. Washington: The World Bank, 1992, p. 1. "governança é definida como a maneira na qual o poder é exercido na gestão dos recursos econômicos e sociais para o desenvolvimento." (tradução nossa).

10 KAUFMANN, D. Repensando a Governança e a Anti-Corrupcão - Ortodoxia Desafiadora. Seminário da Comissão de Ética Pública, IV, 2003, Rio de Janeiro. In: CEZARE, Juliana Pellegrini. Conselhos municipais e governança: uma análise do conselho de representantes de Paranapiacaba e o parque Abdreense do Município de Santo André - SP. Dissertação (Mestrado em Saúde Pública). Faculdade de Saúde Pública. Universidade de São Paulo. São Paulo, 2009, p.47. Disponível em: http://www.fsp.usp.br/siades/documentos/JulianaPellegrini.pdf. Acesso em: 19 de setembro de 2014.

${ }^{11}$ ASSIS, Paloma Carpena de. GODOY, Amalia Maria. O conselho de defesa do meio ambiente de Maringá: governança, poderes e decisões na gestão dos recursos hídricos. Unopar Científica Ciências Jurídicas e Empresariais, Maringá, Vol.9, n.1, p.03, 2008. disponível em: http://revistas.unopar.br/index.php/juridicas/article/view/976/901. Acesso em: 20 de setembro de 2014.
} 
TEIXEIRA, Elisângela Sampaio; CORRALO, Giovani da Silva. Governança local e conselhos municipais - diálogo necessário para sustentabilidade e preservação do meio ambiente. Revista Eletrônica Direito e Política, Programa de Pós-Graduação Stricto Sensu em Ciência Jurídica da UNIVALI, Itajaí, v.10, n.1, edição especial de 2015. Disponível em: www.univali.br/direitoepolitica ISSN 1980-7791.

espacialidade estatal, entretanto, na compreensão da forma como os poderes constituídos conformam e possibilitam o exercício da autoridade. ${ }^{12}{ }^{13}$

Para ter-se uma governança eficiente é preciso ter-se consciência da importância da construção da relação EstadoSociedade. Assim, exige-se não só resultados da administração pública como também transparência e diálogo com a sociedade, disso decorre a importância dos Conselhos Municipais, pois ensina Gonçalves que "A capacidade governativa não seria avaliada apenas pelos resultados das políticas governamentais, e sim também pela forma pela qual o governo exerce o seu poder." ${ }^{14}$ [grifo do autor]. Portanto, o essencial da governança é a participação pública em conjunto com a sociedade civil organizada. Ou seja, não adianta somente atingir os objetivos, o meio pelos quais se atingem tais objetivos também é considerado de suma importância para uma boa governança pública, principalmente quando se fala em questões ambientais, pois estas podem não só refletir no impacto local como também global.

As questões ambientais municipais estão inseridas neste contexto e tornando-se relevante que a governança respeite o princípio da participação democrática participativa e deliberativa. Weiler ${ }^{15}$ cita que o Estado de Direito engloba, entre outras coisas, a pretensão de algo que deve ser justificado e /ou em obediência a lei. Por outro lado, tal obediência ou justificação não pode ser exigida se as leis em questão não emanam de um sistema jurídico integrado com a forma de democracia proposta pelo país.

O autor ressalta que democracia é um dos componentes normativos indispensáveis para legitimar a ordem jurídica. Se a obediência, como uma questão de fato, é assegurada sem a legitimidade que emana das práticas da democracia, não se está mais falando em Estado de Direito. É preciso olhar para as leis para definir se as práticas de democracia na verdade foram seguidas e,

\footnotetext{
12 MATOS, Fernando; DIAS, Reinaldo. Governança Pública: novo arranjo de governo. Campinas: Alínea, 2013, p. 17-24.

${ }^{13}$ STOCKER, Gerry. Governance as theory: five propositions. International Social Science Journal. Vol. 50, p. 17-28, 2002, p. 17.

${ }^{14}$ GONÇALVES, A. O Conceito de Governança. Congresso Nacional do CONDEPI, XVI, 2005, p.01.

${ }^{15}$ WEILER, J. H. H. The Geology of International Law - Governance, Democracy and Legitimacy. Zeitschriftfürausländischesöffentlichesrecht und Völkrecht. Heidelberg,p. 547-562, 2004, p.545 (tradução nossa).
} 
TEIXEIRA, Elisângela Sampaio; CORRALO, Giovani da Silva. Governança local e conselhos municipais - diálogo necessário para sustentabilidade e preservação do meio ambiente. Revista Eletrônica Direito e Política, Programa de Pós-Graduação Stricto Sensu em Ciência Jurídica da UNIVALI, Itajaí, v.10, n.1, edição especial de 2015. Disponível em: www.univali.br/direitoepolitica ISSN 1980-7791.

mais em geral, do Estado de Direito. Restringir o uso arbitrário do poder é um elemento material indispensável da democracia moderna.

No Brasil, o caminho democrático participativo está previsto no Artigo 10 da Constituição Federal que, segundo Hermany ${ }^{16}$, se mostra fundamental e legitima a consolidação de um modelo de relacionamento entre Estado e sociedade. Conforme o autor, é possível dizer que a Constituição Brasileira possibilita a visão governamental que legitima que as decisões públicas devem ser participativas e transparentes. Portanto, não só se deve atingir o resultado, mas sim atingir o resultado de forma a cumprir com os ditames do Estado Democrático de Direito.

Para o referido autor, a democracia participativa não se dá pela dimensão simplória da participação pela participação, devendo se manifestar muito mais pela sua dimensão administrativa. É preciso a participação de grupos e associações no processo de tomada de decisões públicas na esfera local ${ }^{17}$.

Outra característica marcante da governança é a transparência que passa a ser exigida do poder público e está intimamente ligada ao direito à informação previsto na Constituição Federal desde 1988 em seus artigos 50, XIV, XXXIII e XXXIV alínea "a" e "b. Ou seja, desde a Constituição de 1988 esteve assegurado o direito de todos receberem dos órgãos públicos informações de seus interesse particular, ou de interesse coletivo, sob pena de responsabilidade, ressalvadas aquelas cujo sigilo seja imprescindível à segurança da sociedade. A Constituição sempre previu a necessidade de transparência dos atos públicos seja para interesses coletivos ou particulares, com a intenção de mostrar não só a probidade administrativa como também de evitar atos autoritários.

Apesar de garantido pela Constituição Federal, o direito à informação, obtê-la sem transpor barreiras sempre foi um desafio ao cidadão brasileiro, mesmo quando em associação. Ou seja, para que a sociedade consiga informações sobre

\footnotetext{
${ }^{16}$ HERMANY, Ricardo. Município na Constituição, poder local no constitucionalismo luso-brasileiro. Curitiba: Editora Juruá, 2013, p. 63.

${ }^{17}$ HERMANY, Ricardo. Município na Constituição, poder local no constitucionalismo luso-brasileiro, 2013, p. 67.
} 
TEIXEIRA, Elisângela Sampaio; CORRALO, Giovani da Silva. Governança local e conselhos municipais - diálogo necessário para sustentabilidade e preservação do meio ambiente. Revista Eletrônica Direito e Política, Programa de Pós-Graduação Stricto Sensu em Ciência Jurídica da UNIVALI, Itajaí, v.10, n.1, edição especial de 2015. Disponível em: www.univali.br/direitoepolitica ISSN 1980-7791.

a decisões e ações do governo, a dificuldade é extrema, daí decorre a importância da participação cada vez mais ativa da sociedade de forma organizada e nada mais propício a proporcionar tal participação do que as audiências promovidas pelos conselhos municipais.

Outra dimensão proporcionada pela governança é a proposta de accountability que significa que os agentes públicos devem ser responsáveis por sua ações, prestando contas e demonstrando uma total congruência entre as políticas públicas e a alocação eficiente dos recursos públicos. É presente na doutrina o entendimento da accountability vertical e horizontal. A primeira é realizada pelo povo nos processos eleitorais, nos quais os agentes políticos são julgados e avaliados. A segunda é realizada pelos órgãos e instituições que possuem esta atribuição, como é o caso exemplificativo dos tribunais de contas. ${ }^{18}$

Neste sentido, a busca por uma governança transparente tem tornado-se um diferencial para o administrador público. A ONU ${ }^{19}$ tem trabalhado constantemente com projetos e questões que desenvolvam o incentivo e a qualidade da governança pública e manifesta-se se no sentido de que os processos administrativos devem ser democráticos e transparentes o que levaria a uma maior credibilidade e respeito ao cidadão. Reforça que a governança democrática traz avanços ao desenvolvimento através de meios sustentáveis de subsistência. Assim, a ONU proporciona através de vários incentivos e projetos o desenvolvimento e apoio à governança.

E ainda, ressaltando a importância da necessidade da fluidez da governança e participação cidadã, Bauman bem explica que devemos recordar, antes de mais nada, que as "cidades, nas quais vive atualmente mais da metade do gênero humano, são de certa maneira os depósitos onde se descarregam os problemas criados e não resolvidos no espaço global" ${ }^{\prime 20}$, neste sentido, a governança local torna-se imprescindível para dar vazão aos problemas ambientais locais

${ }^{18}$ BENTO, Leonardo Valles. Governança e governabilidade na reforma do Estado: entre eficiência e democratização. Barueri: Manolo, 2003, p. 103-105.

${ }^{19}$ A ONU e a governança. 2014. Disponível em: http://www.onu.org.br/a-onu-em-acao/a-onu-emacao/a-onu-e-a-governanca/. Acesso em: 19 de setembro de 2014.

20 BAUMAN, Zygmunt. Confiança e medo na cidade. Rio de Janeiro: Jorge Zahar. 2009, p. 03. 
TEIXEIRA, Elisângela Sampaio; CORRALO, Giovani da Silva. Governança local e conselhos municipais - diálogo necessário para sustentabilidade e preservação do meio ambiente. Revista Eletrônica Direito e Política, Programa de Pós-Graduação Stricto Sensu em Ciência Jurídica da UNIVALI, Itajaí, v.10, n.1, edição especial de 2015. Disponível em: www.univali.br/direitoepolitica ISSN 1980-7791.

utilizando-se de uma boa governança local, tendo, como um dos focos de atuação, a proteção ao meio ambiente nos termos do art. 225 da Constituição Federal.

\section{Sistema nACIONAL DE MEIO AMBiente E OS CONSELHOS MUNICIPAIS DE MEIO AMBIENTE}

Após diversas transformações sociais e ambientais, o Estado Constitucional de Direito passou a ser normatizador sob a intenção, ao menos é o esperado, no sentido de considerar a sustentabilidade como um pilar da estrutura estatal e, portanto, um direito fundamental de todos à preservação do meio ambiente não só para esta como para gerações futuras, limitando-se, assim, a degradação de recursos finitos que são essenciais a sobrevivência humana e animal ${ }^{21}$.

O Sistema Nacional de Meio Ambiente (SISNAMA) foi instituído em 1982, através da Lei $6.938 / 81^{22}$ e regulamentado pelo Decreto 99.274/90, com o principal objetivo de estabelecer e fortalecer a Política Nacional de Meio Ambiente. Cabe aos Estados, ao Distrito Federal e aos Municípios a regionalização das medidas emanadas do SISNAMA, elaborando normas e padrões supletivos e complementares.

O SISNAMA atua através dos Órgãos e entidades que o constituem. Entre seus órgãos, está o Conselho Nacional do Meio Ambiente (CONAMA) que tem função consultiva e deliberativa. Tem, ainda, o poder de contribuir com a definição de políticas governamentais, através de normas, para a exploração e preservação do meio ambiente e recursos naturais. Emite resoluções, moções e

${ }^{21}$ PILAU SOBRINHO, L. L. ; PAVAN, K. . As novas tecnologias no contexto da sociedade contemporânea, sustentabilidade e desenvolvimento sustentavél. Revista internacional de direito ambiental, v. 2, n. 4 p. $163-185,2013$, p. 173 . Disponível em: http://maestriaderechoambientalucr.files.wordpress.com/2013/12/rida_vol_ii_n06_setdez_2013.pdf. Acesso em: 21 de setembro de 2014.

22 BRASIL. Lei n. 6.938, de 31 de agosto de 1981 . Disponível em: http://www.mma.gov.br/port/conama/legiabre.cfm?codlegi=313. Acesso em: 20 de setembro de 2014. 
TEIXEIRA, Elisângela Sampaio; CORRALO, Giovani da Silva. Governança local e conselhos municipais - diálogo necessário para sustentabilidade e preservação do meio ambiente. Revista Eletrônica Direito e Política, Programa de Pós-Graduação Stricto Sensu em Ciência Jurídica da UNIVALI, Itajaí, v.10, n.1, edição especial de 2015. Disponível em: www.univali.br/direitoepolitica ISSN 1980-7791.

recomendações quando se tratar de implementação de políticas, programas públicos e normas de repercussão na área ambiental.

Os governos locais podem criar conselhos ambientais, podem estabelecer fundos ambientais especiais para promover melhor o uso dos recursos naturais ou apoiar projetos locais ${ }^{23}$. O art. $6^{0}$ da Lei $6.938 / 1981^{24}$ afirma que os conselhos municipais também são órgãos que fazem parte do Sistema Nacional de Meio Ambiente (SISNAMA), tendo que se reportar ao Conama. Ou seja, no plano da legislação federal, o conselho municipal de meio ambiente deve ser regido pelas leis do Conama, no entanto, a lei possibilita ao conselho municipal deliberar, fiscalizar e controlar sobre as questões de meio ambiente, como previsto no art. $60, \mathrm{VI}, \S 20$.

Segundo o Conana, os conselheiros municipais de meio ambiente são pessoas que agem de forma voluntária em benefício da melhoria da qualidade de vida e, portanto, como regra geral, não recebem pagamento pelos serviços prestados. Reforça que cada município deve observar de onde vem a força de representantes do povo, cita como exemplo alguns representantes:

Secretarias municipais de saúde, educação, meio ambiente, obras, planejamento e outras cujas ações interfiram no meio ambiente; Câmara de Vereadores; Sindicatos; Entidades ambientalistas; Grupos de produtores; Instituições de defesa do consumidor; Associações de bairros; Grupos de mulheres, de jovens e de pessoas da terceira idade; Entidades de classe (arquitetos, engenheiros, advogados, professoras etc.); Entidades representativas do empresariado; Instituições de pesquisa e de extensão; Movimentos sociais

23 CAVALCANTI, Clóvis. Economia e ecologia: problemas da governança ambiental no Brasil. Revista Iberoamericana de Economía Ecológica, v. 1, 2004, p.01. http://ddd.uab.cat/pub/revibec/revibec_a2004v1/revibec_a2004v1a5.pdf, Barcelona. Acesso em: 20 de setembro de 2014 .

24 "Art 60 - Os órgãos e entidades da União, dos Estados, do Distrito Federal, dos Territórios e dos Municípios, bem como as fundações instituídas pelo Poder Público, responsáveis pela proteção e melhoria da qualidade ambiental, constituirão o Sistema Nacional do Meio Ambiente - SISNAMA, assim estruturado: (...) VI - Órgãos Locais: os órgãos ou entidades municipais, responsáveis pelo controle e fiscalização dessas atividades, nas suas respectivas jurisdições; (...) § 20 Os Municípios, observadas as normas e os padrões federais e estaduais, também poderão elaborar as normas mencionadas no parágrafo anterior." BRASIL. Lei n. 6.938, de 31 de agosto de 1981. Disponível em: http://www.mma.gov.br/port/conama/legiabre.cfm?codlegi=313. Acesso em: 20 de setembro de 2014. 
TEIXEIRA, Elisângela Sampaio; CORRALO, Giovani da Silva. Governança local e conselhos municipais - diálogo necessário para sustentabilidade e preservação do meio ambiente. Revista Eletrônica Direito e Política, Programa de Pós-Graduação Stricto Sensu em Ciência Jurídica da UNIVALI, Itajaí, v.10, n.1, edição especial de 2015. Disponível em: www.univali.br/direitoepolitica ISSN 1980-7791.

e de minorias que sejam importantes para o município. ${ }^{25}$

O Poder Público Municipal pode fazer concessões a diversos pedidos atinentes a interesses de vários segmentos da sociedade, em nome do interesse local, no entanto, tem obrigação de evitar danos ambientais. Allbrebrandt, ao abordar a natureza dos Conselhos Municipais, afirma que:

(...)são deliberativos, além de consultivos em relação a um conjunto variado de atividades relacionadas à promoção do desenvolvimento local. Os conselhos de todos os municípios preveem entre suas atribuições a elaboração de planos estratégicos de desenvolvimento municipal e a deliberação sobre diretrizes para a política de desenvolvimento municipal, da mesma forma que assumem a função de fiscalização e acompanhamento dos planos e das ações dos governos locais. Podem participar do processo de planejamento, inserindo-se nas dinâmicas adotadas nos municípios, especialmente nas discussões preparatórias e nas audiências públicas organizadas para a elaboração dos instrumentos de gestão pública (PPA, LDO, LOA). ${ }^{26}$

Os conselhos municipais (comudes) possuem o poder não só de serem consultados sobre um determinado assunto como também de participar do processo deliberativo.

No entanto, explica Corralo ${ }^{27}$ que os conselhos deliberativos e os conselhos consultivos devem ser criados por lei municipal e "os municípios possuem autonomia para constituir o número de conselhos necessários para que a população possa participar da gestão pública(...)". Segundo o mesmo autor, a diferença do conselho consultivo e do conselho deliberativo é que neste as deliberações vinculam o gestor público.

25 BRASIL. Conselho Municipal de Meio Ambiente - CMMA. Disponível em: http://www.mma.gov.br/port/conama/conselhos/conselhos.cfm. Acesso em: 19 de setembro de 2014.

26 ALLBEBRANDT, Sérgio Luís. Cidadania e gestão do processo de desenvolvimento: um estudo sobre a atuação dos conselhos regionais e municipais de desenvolvimento do Rio Grande do Sul, de 1990 à 2009. Tese (Doutorado em Desenvolvimento Regional). Programa de Pós Graduação e Desenvolvimento Regional. Universidade de Santa Cruz do Sul. Santa Cruz do Sul, 2010, p. 225.

${ }^{27}$ CORRALO, Giovani da Silva. A democracia participativa nos municípios brasileiros. In: HERMANY, Ricardo (Org.) Empoderamento social local. Santa Cruz do Sul: Editora IPR, 2010, p.289-306. 
TEIXEIRA, Elisângela Sampaio; CORRALO, Giovani da Silva. Governança local e conselhos municipais - diálogo necessário para sustentabilidade e preservação do meio ambiente. Revista Eletrônica Direito e Política, Programa de Pós-Graduação Stricto Sensu em Ciência Jurídica da UNIVALI, Itajaí, v.10, n.1, edição especial de 2015. Disponível em: www.univali.br/direitoepolitica ISSN 1980-7791.

Por isso, trata-se relevante discutir o impacto de mudanças ambientais e pensar no interesse local da comunidade através do diálogo com os conselhos municipais, cita-se, como exemplo, a necessidade de transparência ao Conselho Municipal de Meio Ambiente, conforme previsto no Estatuto da Cidade, art. 36 e 37 parágrafo único, que prevê o Estudo de Impacto de Vizinhança sobre algum projeto construtivo. Trata-se de um instrumento que permite promover a mediação de interesses dos investidores imobiliários, gestores públicos e sociedade, onde este estudo, feito por professional especializado, ficará à disposição para consulta e questionamentos que, por conseguinte, poderá ser discutido em audiência perante o Conselho Municipal de Meio Ambiente, sendo que poderá ser analisado juntamente com o Estudo de Impacto Ambiental (Conama Resolução no. 01/86).

Cabe ainda destacar que os municípios possuem autonomia políticoadministrativa para administrar e repassar recursos aos conselhos, conforme art. 18 da CF. Ensina Maffini ${ }^{28}$ que "não se atribui a União (por exemplo, no art. 22 da CF) uma competência geral de legislação sobre o Direito Administrativo, impõem-se a conclusão de que, como regra, cada ente federal detém competência para legislar sobre os assuntos de seus respectivos interesses."

Quanto a obrigação do município em relação à competência material, o art. 225, cominado com o art. 23, VI da Constituição Federal, determina a competência comum dos entes federados na proteção do meio ambiente. Ou seja, é competência também do município fazer políticas públicas que combatam e evitem a violação ao meio ambiente.

Fica margens para discussões e interpretações no que tange à matéria para o município legislar sobre matéria ambiental, pois tal como exposto no art. 24, incisos VI, VII, VIII, IX e XI da CF que estabelece competência concorrente 'a União, Estados e DF e para legislar sobre material ambiental, na tentativa de proporcionar a todos um meio ambiente ecologicamente equilibrado, como preconiza o art. 225 da Carta Magna.

${ }^{28}$ MAFFINI, Rafael. Direito Administrativo. 3 ed. Rio de Janeiro: Editora dos Tribunais, 2010, p. 21-34. 
TEIXEIRA, Elisângela Sampaio; CORRALO, Giovani da Silva. Governança local e conselhos municipais - diálogo necessário para sustentabilidade e preservação do meio ambiente. Revista Eletrônica Direito e Política, Programa de Pós-Graduação Stricto Sensu em Ciência Jurídica da UNIVALI, Itajaí, v.10, n.1, edição especial de 2015. Disponível em: www.univali.br/direitoepolitica ISSN 1980-7791.

Consoante ao art. 24 da Constituição Federal, Magalhães ${ }^{29}$ e também Costa ${ }^{30}$ explicam que havendo conflito entre as leis de diferente competência prevalece a da União sobre a do Estado ou a do Município, e, ainda, prevalece a do Estado sobre a do Município. O limite para a competência concorrente esbarra na não manifestação da União sobre determinado assunto ambiental, se a União não se manifestar sobre o assunto, então o Estado poderá se manifestar conforme seu interesse, é uma forma de competência supletiva. Ou seja, há uma competência concorrente, porém de forma supletiva, caso a União não se manifesta, ou se manifestar, é o que estará prevalecendo.

\section{A busCa pelo amadurecimento entre governança pública e CONSELHO MUNICIPAL DO MEIO AMBIENTE}

A participação popular está definida na CF, em seu art.29, XII, que prevê a cooperação das associações representativas no planejamento municipal. Para regulamentar as normas pertinentes à gestão democrática das políticas públicas previstas na Constituição, leis ordinárias instituem conselhos gestores que devem ajudar e participar da gestão pública.

O poder público municipal através dos princípios da governança deve promover o crescimento econômico sem, no entanto, promover um desequilíbrio ecológico e violar leis ambientais. Inevitável é o crescimento econômico, o problema é, como afirma Cavalcanti ${ }^{31}$ "A fé na ideia de crescimento econômico ilimitado exerce fascínio insuperável e parece particularmente enraizada na mente coletiva nacional, especialmente entre as elites econômicas."

Neste diapasão, buscar-se um equilíbrio entre estas duas vertentes, ou seja, é

\footnotetext{
29 MAGALHÃES, Vladimir Garcia. Competência concorrente em matéria ambiental: proteção ao meio ambiente e justiça. Revista Brasileira de Direito Constitucional. São Paulo, v. 2, 2003, p. 148. Disponível em: http://esdc.com.br/seer/index.php/rbdc/article/view/44, acesso em 22 de setembro de 2014. Acesso em 21 de setembro de 2014.
}

${ }^{30}$ COSTA, Nelson Nery. ALVES, Geraldo Magela. Constituição Federal anotada e explicada. 3 ed. Rio de Janeiro: Editora Forense, 2006, p.92.

${ }^{31}$ CAVALCANTI, Clóvis. Economia e ecologia: problemas da governança ambiental no Brasil. Revista Iberoamericana de Economía Ecológica, v. 1, 2013, p.01. 
TEIXEIRA, Elisângela Sampaio; CORRALO, Giovani da Silva. Governança local e conselhos municipais - diálogo necessário para sustentabilidade e preservação do meio ambiente. Revista Eletrônica Direito e Política, Programa de Pós-Graduação Stricto Sensu em Ciência Jurídica da UNIVALI, Itajaí, v.10, n.1, edição especial de 2015. Disponível em: www.univali.br/direitoepolitica ISSN 1980-7791.

desafiador exercer governança transparente e participativa através de negociação e diálogo com diferentes grupos, poder executivo, poder legislativo e conselhos municipais. As políticas públicas municipais não podem fugir da responsabilidade de promover o desenvolvimento econômico, o problema está em realizar isso a qualquer custo, olvidando-se de cumprir com as normas estabelecidas pelo Estado Democrático de Direito.

E o exercício da governança participativa, na prática, sem dúvida encontra-se desafios, cita-se como caso exemplificativo o trabalho realizado por Schelee ${ }^{32}$ que avaliou a legislação vigente na cidade do Rio de Janeiro com vistas a orientar e controlar a ocupação das encostas. Realizaram reflexões decorrentes de um estudo abrangente, de confrontação das legislações urbanísticas, de proteção ambiental e de proteção cultural, elaborado no âmbito da Secretaria Municipal de Urbanismo da Prefeitura da Cidade do Rio de Janeiro.

Constataram conflitos quanto a conceito e terminologias utilizadas nas diversas legislações que abordam o assunto em nível municipal, e destaca-se: dentro do mesmo município! Também constataram a exígua participação da sociedade no processo de proteção e valorização do patrimônio natural e cultural em âmbito local. Afirmam que se percebeu uma metodologia "(...) incipiente em termos de planejamento e gestão ambiental, imposta pela racionalidade administrativa que privilegia intervenções caso a caso, e na qual a participação da sociedade se dá de modo eventual, através de consultas à população." ${ }^{33}$

Importante pesquisa realizada por Carvalho e Castro ${ }^{34}$ sobre a atuação dos Conselhos Municipais de Salvador, apresenta alguns problemas enfrentados para

32 SCHLEE, Mônica Bahia; ALBERNAZ, Maria Paula. Proteção das Encostas pela Legislação Municipal: uma avaliação da situação atual na cidade do Rio de Janeiro. Anais: Encontros Nacionais da ANPUR, Rio de Janeiro, v. 13, 2013, p. 21. Disponível em: http://www.anpur.org.br/revista/rbeur/index.php/anais/article/view/2772. Acesso em 21 de setembro de 2014.

33 SCHLEE, Mônica Bahia; ALBERNAZ, Maria Paula. Proteção das Encostas pela Legislação Municipal: uma avaliação da situação atual na cidade do Rio de Janeiro, 2013, p. 20.

34 DE CARVALHO, Juvenilda Soares. Conselhos municipais: sua contribuição para o desenvolvimento local. Anais: Encontros Nacionais da ANPUR, v. 8, 2013, p.7-8. Disponível em: http://www.anpur.org.br/revista/rbeur/index.php/anais/article/download/1854/1821. Acesso em: 22 de setembro de 2014. 
TEIXEIRA, Elisângela Sampaio; CORRALO, Giovani da Silva. Governança local e conselhos municipais - diálogo necessário para sustentabilidade e preservação do meio ambiente. Revista Eletrônica Direito e Política, Programa de Pós-Graduação Stricto Sensu em Ciência Jurídica da UNIVALI, Itajaí, v.10, n.1, edição especial de 2015. Disponível em: www.univali.br/direitoepolitica ISSN 1980-7791.

dar efetividade a existência deste órgão. Há uma série de dificuldades, de diversas ordens. Entre os mais importantes problemas detectados, está a falta de conhecimento dos conselheiros, pois possuem conhecimento de atribuições básicas de seus cargos, mas não têm compreensão de questões mais aprofundadas, como, por exemplo, a compreensão do conceito de cidadania. Percebeu-se também um desconhecimento da lógica do funcionamento da máquina pública e da burocracia, além disso, atuam mais homologadores do que propositores.

Os mesmos autores colocam que há também uma resistência governamental em ouvir os órgãos de representação da sociedade e não raras vezes decidindo dentro de um modelo autoritário. Incapacidades de negociação por desconhecimento político administrativa. A dependência que os conselhos têm de repasses de recursos municipais para sua manutenção, na medida em que não são, nem devem ser órgãos executores, dificulta o exercício de sua função. Sem os recursos necessários, sua ação torna-se superficial, incapaz de atingir os interesses coletivos, resvalando portanto para uma postura meramente homologatória de propostas que, na maioria das vezes, não refletem os reais interesses da sociedade.

Pesquisa semelhante foi realizada por Cesare ${ }^{35}$ sobre o Conselho Municipal de Meio Ambiente de Santo André, SP, a autora concluiu que o baixo nível de escolaridade da sociedade civil acaba comprometendo a qualidade da participação, como, por exemplo, quando trata-se de questões de mananciais, legislação ambiental - áreas em que é exigido uma maior compreensão técnica. A autora destaca inclusive disparidade de nível de escolaridade apresentada entre os conselheiros do poder público e da sociedade civil, dificulta o relacionamento entre os dois, podendo ser causa do desânimo e do descrédulo por parte da população da sua real participação, o que pode gerar descrença e desmotivação por parte da sociedade.

\footnotetext{
${ }^{35}$ CEZARE, Juliana Pellegrini. Conselhos municipais e governança: uma análise do conselho de representantes de Paranapiacaba e o parque Abdreense do Município de Santo André - SP, p.141. Disponível em: http://www.fsp.usp.br/siades/documentos/JulianaPellegrini.pdf, acesso em: 19 de setembro de 2014. Acesso em 22 de setembro de 2014.
} 
TEIXEIRA, Elisângela Sampaio; CORRALO, Giovani da Silva. Governança local e conselhos municipais - diálogo necessário para sustentabilidade e preservação do meio ambiente. Revista Eletrônica Direito e Política, Programa de Pós-Graduação Stricto Sensu em Ciência Jurídica da UNIVALI, Itajaí, v.10, n.1, edição especial de 2015. Disponível em: www.univali.br/direitoepolitica ISSN 1980-7791.

Ademais, afirma Cavalcanti ${ }^{36}$ que o sucesso dos conselhos ambientais depende do peso político, via de regra pequeno, dessa instância dentro das administrações locais ou da intensidade, normalmente baixa, com que nelas manifestam-se sentimentos verdes. Outro fator importante destacado pelo autor é a falta de interesse do município em criar legislação sobre áreas de interesse especial.

Os casos descritos acima são reflexos de uma democracia inconsistente e resultado de uma relação onde fica evidente que a estratégia de participação democrática da sociedade ainda está em processo de construção e amadurecimento, pois sinaliza que há uma grande distância entre sua concepção, do ponto de vista do discurso e a forma concreta com que se operacionalizam os procedimentos cotidianos. Deve a sociedade fortalecer tal vínculo para consolidar o espaço que se abriu para a participação popular.

\section{CONSIDERAÇÕES FINAIS}

A Constituição de 1988 propiciou a ampliação de espaços de participação popular permitindo a sociedade manifestar-se sobre a gestão das políticas públicas. Significa superar o clássico modelo da democracia representativa para avançar no caminho da democracia participativa, calcada numa efetiva participação e controle social sobre as atividades dos poderes constituídos.

E, acima de tudo, só se é comunidade quando há compartilhamento de ideias e cuidados mútuo, uma comunidade de interesse e de responsabilidade em relação aos direitos iguais de sermos humanos e com igual capacidade de agirmos em defesa desses direitos ${ }^{37}$, isso vale para o diálogo entre meio ambiente e governança.

\footnotetext{
${ }^{36}$ CAVALCANTI, Clóvis. Economia e ecologia: problemas da governança ambiental no Brasil. Revista Iberoamericana de Economía Ecológica, v. 1, 2013, p. 05.

37 BAUMAN, Zygmunt. Comunidade: a busca por segurança no mundo atual. Rio de Janeiro: Jorge Zahar. 2003, p. 134.
} 
TEIXEIRA, Elisângela Sampaio; CORRALO, Giovani da Silva. Governança local e conselhos municipais - diálogo necessário para sustentabilidade e preservação do meio ambiente. Revista Eletrônica Direito e Política, Programa de Pós-Graduação Stricto Sensu em Ciência Jurídica da UNIVALI, Itajaí, v.10, n.1, edição especial de 2015. Disponível em: www.univali.br/direitoepolitica ISSN 1980-7791.

Nestas últimas três décadas, a expressão governança exsurge com conteúdo próprio, impulsionada pelos trabalhos do Banco Mundial. Aparta-se do conceito de governo e governabilidade, adstritas à espacialidade eminentemente estatal, para abarcar um contexto de significados muito mais amplo, cimentado num efetivo Estado de Direito, na democracia participativa, na transparência e na accountability.

Estas quatro dimensões da governança entrelaçam-se na conformação do seu conteúdo, entretanto, não há como não relevar a dimensão da democracia participativa, fortemente presente nos conceitos forjados pelos organismos internacionais e pelos estudiosos da temática. É por essa razão que se enfatiza a necessária e imprescindível abertura para que os cidadãos, a sociedade civil organizada e os atores econômicos possam participar ativamente do processo de elaboração, execução, monitoramento e avaliação de políticas públicas. A espacialidade estatal, mormente a administração pública, não pode bastar a si mesma; não pode estar hermeticamente fechada, sem auscultar a sociedade em geral e, mais especificamente, as pessoas atingidas por ações e políticas públicas.

As políticas ambientais não fogem a esta regra. Ao contrário. Além do dever de efetivar o compromisso constitucional com o desenvolvimento sustentável, logo, preservador dos recursos naturais, deve permitir a concretização de projetos desenvolvimentistas impulsionados pelas pessoas políticas, seja o Município, o Estado, o Distrito Federal ou a União. Não é sem razão que uma das formas de intervenção do Estado na atividade econômica ocorre, nos termos do art. 174 da Constituição, através do planejamento, da fiscalização e do incentivo, o que abarca os diversos estímulos ao desenvolvimento econômico e, também, o exercício da polícia administrativa através do licenciamento de atividades. Neste último exemplo que o licenciamento ambiental enquadra-se, realizado com o fim de garantir a sustentabilidade do desenvolvimento.

Não é sem razão que o direito ao meio ambiente é um direito fundamental. Não é sem motivo que se trata de um mister da competência de todos os entes federados, seja na órbita legislativa, seja na dimensão administrativa. É por isso 
TEIXEIRA, Elisângela Sampaio; CORRALO, Giovani da Silva. Governança local e conselhos municipais - diálogo necessário para sustentabilidade e preservação do meio ambiente. Revista Eletrônica Direito e Política, Programa de Pós-Graduação Stricto Sensu em Ciência Jurídica da UNIVALI, Itajaí, v.10, n.1, edição especial de 2015. Disponível em: www.univali.br/direitoepolitica ISSN 1980-7791.

que, ao mesmo tempo que todas as esferas da Federação podem dispor de estímulos ao desenvolvimento, há o dever inescusável de somente permitir o funcionamento e a operação daquelas atividades que não coloquem em risco o futuro. Mais do que isso, permite-se a cada ente federado a elaboração de normas ambientais vinculadas a esse fim.

A governança é fortemente alavancada através das diversas instâncias de participação popular, nas quais os conselhos municipais do meio ambiente são exemplos concretos. A instituição desses conselhos em nível local faz com que o governo e representantes da sociedade civil dialoguem e construam políticas consoante a sustentabilidade desenvolvimentista almejada. Além disso, permitem o controle das políticas municipais do meio ambiente.

Neste diapasão, governança, participação popular e sustentabilidade imbricamse para dar concretude ao Estado Democrático de Direito consubstanciado na Constituição de 1988. Uma efetiva governança ambiental local possui, nos conselhos municipais, um locus privilegiado para uma democrática gestão das políticas ambientais de competência da municipalidade.

\section{REFERÊNCIAS DAS FONTES CITADAS}

ALLBEBRANDT, Sérgio Luís. Cidadania e gestão do processo de desenvolvimento: um estudo sobre a atuação dos conselhos regionais e municipais de desenvolvimento do Rio Grande do Sul, de 1990 à 2009. Tese (Doutorado em Desenvolvimento Regional). Programa de Pós Graduação e Desenvolvimento Regional. Universidade de Santa Cruz do Sul. Santa Cruz do Sul. 2010.

ASSIS, Paloma Carpena de. GODOY, Amalia Maria. O conselho de defesa do meio ambiente de Maringá: governança, poderes e decisões na gestão dos recursos hídricos. Unopar Científica Ciências Jurídicas e Empresariais, Maringá, Vol.9, n.1, p.03, $2008 . \quad$ disponível em: http://revistas.unopar.br/index.php/juridicas/article/view/976/901, acesso em: 20 de setembro de 2014.

BASTOS, Cleverson Leite. KELLER, Vicente. Aprendendo a aprender: introdução à metodologia científica. Petrópolis, RJ: Editora Vozes, 2008, p.60.

BAUMAN, Zygmunt. Comunidade: a busca por segurança no mundo atual. Rio de 
TEIXEIRA, Elisângela Sampaio; CORRALO, Giovani da Silva. Governança local e conselhos municipais - diálogo necessário para sustentabilidade e preservação do meio ambiente. Revista Eletrônica Direito e Política, Programa de Pós-Graduação Stricto Sensu em Ciência Jurídica da UNIVALI, Itajaí, v.10, n.1, edição especial de 2015. Disponível em: www.univali.br/direitoepolitica ISSN 1980-7791.

Janeiro: Jorge Zahar. 2003, p. 134.

BAUMAN, Zygmunt. Confiança e medo na cidade. Rio de Janeiro: Jorge Zahar. 2009, p. 134.

BENTO, Leonardo Valles. Governança e governabilidade na reforma do Estado: entre eficiência e democratização. Barueri: Manolo, 2003, p. 103-105.

BRASIL. Constituição da República Federativa do Brasil de 05 de outubro de $1988 . \quad$ Disponível em: http://www.planalto.gov.br/ccivil_03/constituicao/constituicao.htm, acesso em: 22 de setembro de 2014.

. Lei n. 6.938, de 31 de agosto de 1981. Disponível em: http://www.mma.gov.br/port/conama/legiabre.cfm?codlegi=313, acesso em: 20 de setembro de 2014.

Lei n. 10.257 de 10 de julho de 2001. Disponível em: http://www.planalto.gov.br/ccivil_03/leis/leis_2001//10257.htm, acesso em 21 de setembro de 2014.

Conselho Municipal de Meio Ambiente - CMMA. Disponível em: http://www.mma.gov.br/port/conama/conselhos/conselhos.cfm, acesso em: 19 de setembro de 2014.

Supremo Tribunal Federal. Acordão. Ação Direta de Inconstitucionalidade n. 3540. Relator: MELLO, Celso de. Tribunal Pleno, Publicado no DJ de 03-02-2006; EMENTA V. 02219-03 PP-00528, disponível em: http://www.stf.jus.br/portal/principal/principal.asp, acesso em: 22 de setembro de 2014.

CANOTILHO, José Joaquim Gomes. LEITE, José Rubens Morato. Direito constitucional ambiental brasileira. 3. ed. São Paulo: Editora Saraiva, 2010, p.215.

CAVALCANTI, Clóvis. Economia e ecologia: problemas da governança ambiental no Brasil. Revista Iberoamericana de Economía Ecológica, v. 1, 2004, p.110. http://ddd.uab.cat/pub/revibec/revibec_a2004v1/revibec_a2004v1a5.pdf, Barcelona.

CEZARE, Juliana Pellegrini. Conselhos municipais e governança: uma análise do conselho de representantes de Paranapiacaba e o parque Abdreense do Município de Santo André - SP. Dissertação (Mestrado em Saúde Pública). Faculdade de Saúde Pública. Universidade de São Paulo. São Paulo, 2009, Disponível em: http://www.fsp.usp.br/siades/documentos/JulianaPellegrini.pdf, acesso em: 19 de setembro de 2014.

CORRALO, Giovani da Silva. A democracia participativa nos municípios brasileiros. In: HERMANY, Ricardo (Org.). Empoderamento social local. Santa Cruz do Sul: Editora IPR, 2010, p.289-306. 
TEIXEIRA, Elisângela Sampaio; CORRALO, Giovani da Silva. Governança local e conselhos municipais - diálogo necessário para sustentabilidade e preservação do meio ambiente. Revista Eletrônica Direito e Política, Programa de Pós-Graduação Stricto Sensu em Ciência Jurídica da UNIVALI, Itajaí, v.10, n.1, edição especial de 2015. Disponível em: www.univali.br/direitoepolitica ISSN 1980-7791.

COSTA, Nelson Nery. ALVES, Geraldo Magela. Constituição Federal anotada e explicada. 3 ed. Rio de Janeiro: Editora Forense, 2006, p.92.

DE CARVALHO, Juvenilda Soares. Conselhos municipais: sua contribuição para o desenvolvimento local. Anais: Encontros Nacionais da ANPUR, v. 8, 2013, p.1-9.

Disponível

em: http://www.anpur.org.br/revista/rbeur/index.php/anais/article/download/1854/1 821, acesso em: 22 de setembro de 2014.

GONÇALVES, A. O Conceito de Governança. Congresso Nacional do CONDEPI, XIV, 2005, Fortaleza. Anais. Florianópolis: Fundação Boileux; 2006.

GUSTIN, Miracy Barbosa de Souza. DIAS, Maria Tereza Fonseca. (Re)pensando a pesquisa jurídica: teoria e prática. Belo Horizonte, $\mathrm{BH}$ : Editora Del Rey, 2010, p.106.

HERMANY, Ricardo. Município na Constituição, poder local no constitucionalismo luso-brasileiro. Curitiba: Editora Juruá, 2013, p. 63.

KAUFMANN, D. Repensando a Governança e a Anti-Corrupção - Ortodoxia Desafiadora. Seminário da Comissão de Ética Pública, IV, 2003, Rio de Janeiro. In: CEZARE, Juliana Pellegrini. Conselhos municipais e governança: uma análise do conselho de representantes de Paranapiacaba e o parque Abdreense do Município de Santo André - SP. Dissertação (Mestrado em Saúde Pública). Faculdade de Saúde Pública. Universidade de São Paulo. São Paulo, 2009. Disponível em: http://www.fsp.usp.br/siades/documentos/JulianaPellegrini.pdf, , acesso em: 19 de setembro de 2014.

MAFFINI, Rafael. Direito Administrativo. 3 ed. Rio de Janeiro: Editora dos Tribunais, 2010, p. 21-34.

MAGALHÃES, Vladimir Garcia. Competência concorrente em matéria ambiental: proteção ao meio ambiente e justiça. Revista Brasileira de Direito Constitucional. São Paulo, v. 2, 2003, p. 148. Disponível em: http://esdc.com.br/seer/index.php/rbdc/article/view/44, acesso em 22 de setembro de 2014.

MATOS, Fernando; DIAS, Reinaldo. Governança Pública: novo arranjo de governo. Campinas: Alínea, 2013, p.17-24.

ORGANIZAÇÃO DA NAÇÕES UNIDAS. A ONU e a governança. 2014. Disponível em: http://www.onu.org.br/a-onu-em-acao/a-onu-em-acao/a-onu-e-agovernanca/, acesso em: 19 de setembro de 2014.

PILAU SOBRINHO, L. L. ; PAVAN, K. . As novas tecnologias no contexto da sociedade contemporânea -sustentabilidade e desenvolvimento sustentavél. Revista internacional de direito ambiental, v. 2, n. 4 p. 163-185, 2013. Disponível

em: 
TEIXEIRA, Elisângela Sampaio; CORRALO, Giovani da Silva. Governança local e conselhos municipais - diálogo necessário para sustentabilidade e preservação do meio ambiente. Revista Eletrônica Direito e Política, Programa de Pós-Graduação Stricto Sensu em Ciência Jurídica da UNIVALI, Itajaí, v.10, n.1, edição especial de 2015. Disponível em: www.univali.br/direitoepolitica ISSN 1980-7791.

http://maestriaderechoambientalucr.files.wordpress.com/2013/12/rida_vol_ii_n0 6_set-dez_2013.pdf, acesso em: 21 de setembro de 2014.

STOCKER, Gerry. Governance as theory: five propositions. International Social Science Journal, v. 50, 2002, p. 17-28.

SCHLEE, Mônica Bahia; ALBERNAZ, Maria Paula. Proteção das Encostas pela Legislação Municipal: uma avaliação da situação atual na cidade do Rio de Janeiro. Anais: Encontros Nacionais da ANPUR, Rio de Janeiro, v. 13, 2013, p. $21 . \quad$ Disponível em: http://www.anpur.org.br/revista/rbeur/index.php/anais/article/view/2772, acesso em 21 de setembro de 2014.

SCHLEE, Mônica Bahia; AlBernAZ, Maria Paula. Proteção das Encostas pela Legislação Municipal: uma avaliação da situação atual na cidade do Rio de Janeiro, 2013, p. 20.

WEILER, J. H. H. The Geology of International Law - Governance, Democracy and Legitimacy. Zeitschriftfürausländischesöffentlichesrecht und Völkrecht. Heidelberg,p. 547-562, 2004, p.545 (tradução nossa).

WORLD BANK. Governance and Development. Washington: The World Bank, 1992 , p. 1. "governança é definida como a maneira na qual o poder é exercido na gestão dos recursos econômicos e sociais para o desenvolvimento." (tradução nossa).

Submetido em: Setembro/2014

Aprovado em: Outubro/2014 